\title{
Separation of Lactic Acid from Diluted Solution by Hybrid Short Path Evaporation and Reactive Distillation
}

\author{
Andrea Komesu ${ }^{1}$, Johnatt Allan Rocha de Oliveira ${ }^{2}$, Maria Regina Wolf Maciel ${ }^{1}$ and Rubens Maciel Filho ${ }^{1}$ \\ 1. School of Chemical Engineering, University of Campinas (UNICAMP), Box: 6066, Campinas-SP, 13083970, Brazil \\ 2. Nutrition College, Federal University of Pará (UFPA), Belém-PA, 66075110, Brazil
}

\begin{abstract}
This work describes the separation and purification of lactic acid from diluted solution by HSPE (hybrid short path evaporation) and RD (reactive distillation) as coupled process. The results showed that it is possible to increase lactic acid concentration up to 4.7 times higher than the raw material concentration.
\end{abstract}

Key words: Lactic acid, hybrid short path evaporation, reactive distillation, separation processes.

\section{Introduction}

Lactic acid, which is one of the most important commodity chemicals, is a natural organic acid with a long history of applications in food, pharmaceutical, textile, cosmetic and chemical industries [1, 2]. In recent years, the demand for lactic acid has been increasing considerably owing to its use as a monomer in the preparation of biodegradable and biocompatible polymer, i.e. PLA (polylactic acid) [1, 3], and used as feedstock to produce derivatives such as ethyl esters, which is used to replace hazardous solvents like chlorinated hydrocarbon solvents in certain industrial applications [4].

Two methods are currently used to produce lactic acid, where one involves chemical synthesis that yields only DL-lactic acid, and the other involves biological fermentation that can yield a particular lactic acid (L- or D- lactic acid) by selecting specific microorganisms, substrates, and conditions [5].

Biological production of lactic acid has become preferred because physical and mechanical properties of PLA are strongly affected by optical purity of lactic acid [6]. In addition, renewable and low cost raw materials, such as sugarcane molasses, kitchen waste,

Corresponding author: Andrea Komesu, Ph.D., research field: chemical engineering. paper sludge, agriculture wastes, and others, can be used as substrates for lactic acid production.

The main problem in the production of lactic acid by fermentation is its separation and purification. Therefore, development of an efficient and low cost downstream processing is very important, since this can reach up to $50 \%$ of the total cost [7-9].

A considerable number of researches were carried out on finding attractive separation technique for the recovery of lactic acid from fermentation broth, such as precipitation [10-12], solvent extraction [13-15], membrane separation processes, such as reverse osmosis, electrodialysis and ultrafiltration [16-18], molecular distillation [19-21], reactive distillation [22-24], and others. Among proposed technologies, molecular distillation (or short path evaporation) may have advantages: short residence time in the zone of the molecular evaporator exposed to heat and low operating temperature due to vacuum in the space of distillation [25], which minimizes problems with thermal decomposition. Reactive distillation has been proposed as a promising technique because it fulfils the overall objectives of process intensification [26], and the use for separation and purification of lactic acid produced by fermentation is extremely beneficial.

The employment of new purification technologies and integrated process configurations presents 
exciting possibilities to reduce the number of purification steps and production costs [27]. So, the objective of this work was to evaluate the lactic acid purification using HSPE (hybrid short path evaporation) and RD (reactive distillation) as coupled process.

\section{Experiment}

\subsection{Materials}

Lactic acid $85 \%$ supplied by Ecibra (São Paulo, Brazil) was diluted with distilled water (4.71 wt \%). Ethanol 99.5\% was supplied by Dinâmica (São Paulo, Brazil) and sulfuric acid $95-97 \%$ used as catalyst was supplied by Ecibra (São Paulo, Brazil). Standard solutions of ethyl lactate $98 \%$ and DL-lactic acid $90 \%$ supplied by Sigma-Aldrich (St. Louis, Missouri, EUA) were used to build the calibration curve for ethyl lactate and lactic acid quantification, respectively.

\subsection{Analytical Methods}

Analyses of lactic acid were performed in an equipment of HPLC (high performance liquid chromatography), Agilent model 1260, equipped with UV detector (UV-vis) connected in series with the chromatography column Bio-Rad Aminex, model HPX-87H $(300 \times 7.8 \mathrm{~mm})$. The equipment was controlled through Open Lab software.

Sulfuric acid solution with $5 \mathrm{mM}$ was used as mobile phase at flow rate of $0.6 \mathrm{~mL} / \mathrm{min}$. The column temperature was kept constant at $37^{\circ} \mathrm{C}$. An injection volume of $25 \mu \mathrm{L}$ was used in each run. For lactic acid detection and quantification, the wavelength of 215 $\mathrm{nm}$ was used in the UV detection system [20].

Analyses of ethyl lactate were performed in an equipment of GC (gas chromatography), Agilent Technologies model 7890A, equipped with FID (flame ionization detector) and a DB-FFAP column $(30 \mathrm{~m} \times 250 \mu \mathrm{m} \times 0.25 \mu \mathrm{m})$. The column program heating was $100-125{ }^{\circ} \mathrm{C}$ at $2.5{ }^{\circ} \mathrm{C} / \mathrm{min}$ and held temperature constant at $125{ }^{\circ} \mathrm{C}$ for $4 \mathrm{~min}$. Helium ( $99.9 \%$ purity) was used as carrier gas at a flow rate of
$3 \mathrm{~mL} / \mathrm{min}$. The injector and the detector temperatures were maintained at $240{ }^{\circ} \mathrm{C}$ and $250{ }^{\circ} \mathrm{C}$, respectively. In each run, an injection volume of $1 \mu \mathrm{L}$ was used [28].

\subsection{Hybrid Short Path Evaporation System}

In this work an evaporation system composed by a molecular distiller, Model Pope 2 Wiped Film Still, manufactured by Pope Scientific Inc. (Saukville, WI, USA) associated with an external condenser, as shown in Fig. 1, was used to study lactic acid purification. Because of the addition of the external condenser, the system was named HSPE (hybrid short path evaporation). Table 1 describes the characteristics of the HSPE.

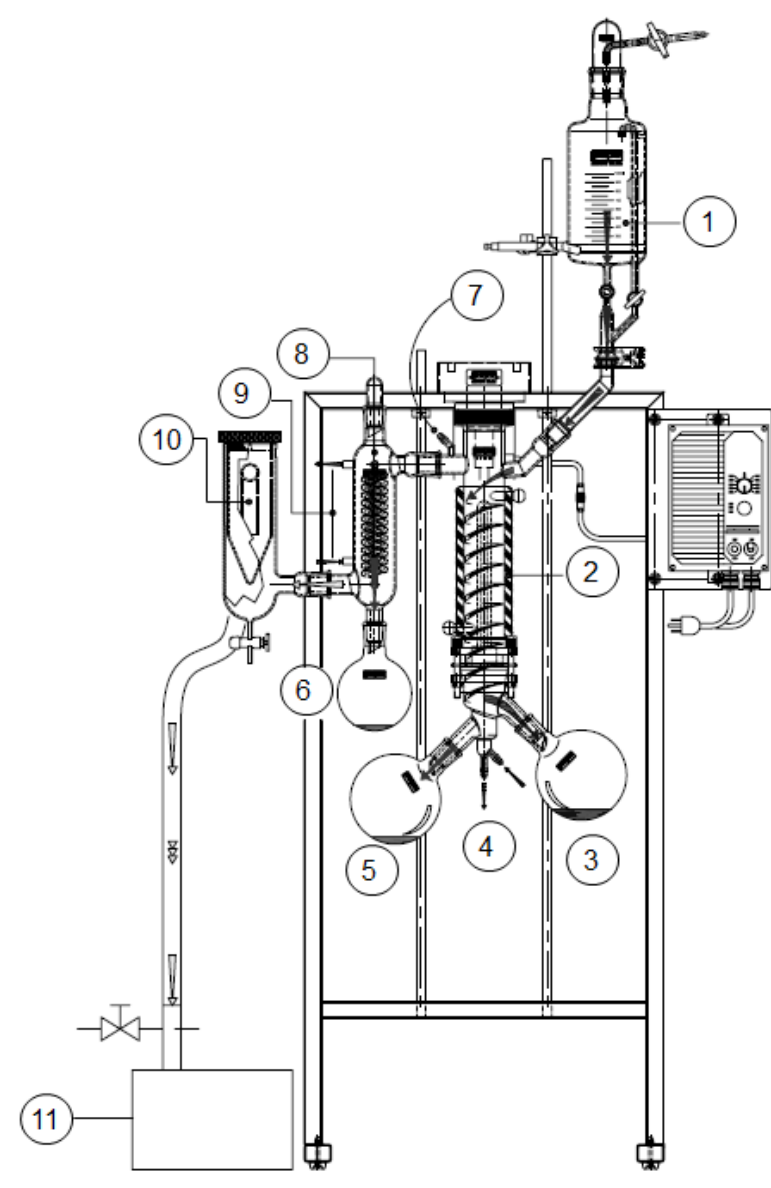

Fig. 1 Hybrid short path evaporation system. (1) feed; (2) electric jacket; (3) residue; (4) coolant; (5) internal condenser distillate; (6) external condenser distillate; (7) vacuum gauge; (8) external condenser; (9) coolant; (10) cold trap; (11) vacuum pump. 
Table 1 Characteristics of the hybrid short path evaporation system.

\begin{tabular}{|l|l|}
\hline Evaporator type & Short path \\
\hline Condenser & External and internal \\
\hline Agitation & With \\
\hline $\mathrm{D}^{*}(\mathrm{~mm})$ & 17 \\
\hline Evaporation surface $\left(\mathrm{m}^{2}\right)$ & 0.033 \\
\hline Heating system & Electric \\
\hline
\end{tabular}

$\mathrm{D}^{*}=$ Distance between evaporator-internal condenser $(\mathrm{mm})$.

\subsection{Reactive Distillation System}

The RD (reactive distillation system) is composed by a tray column of Fischer ${ }^{\circledR}$ Labodest ${ }^{\circledR}$ (Waldbuttelbrunn, Germany), as shown in Fig. 2. The reactive distillation column consists of 10 Oldershaw type plates, made in borosilicate glass. The plate distance is $30 \mathrm{~mm}$ with dynamic hold-up per plate of 2 $\mathrm{mL}$ and static hold up of $0.2 \mathrm{~mL}$. The column had a silvered vacuum jacket for thermal isolation [30].

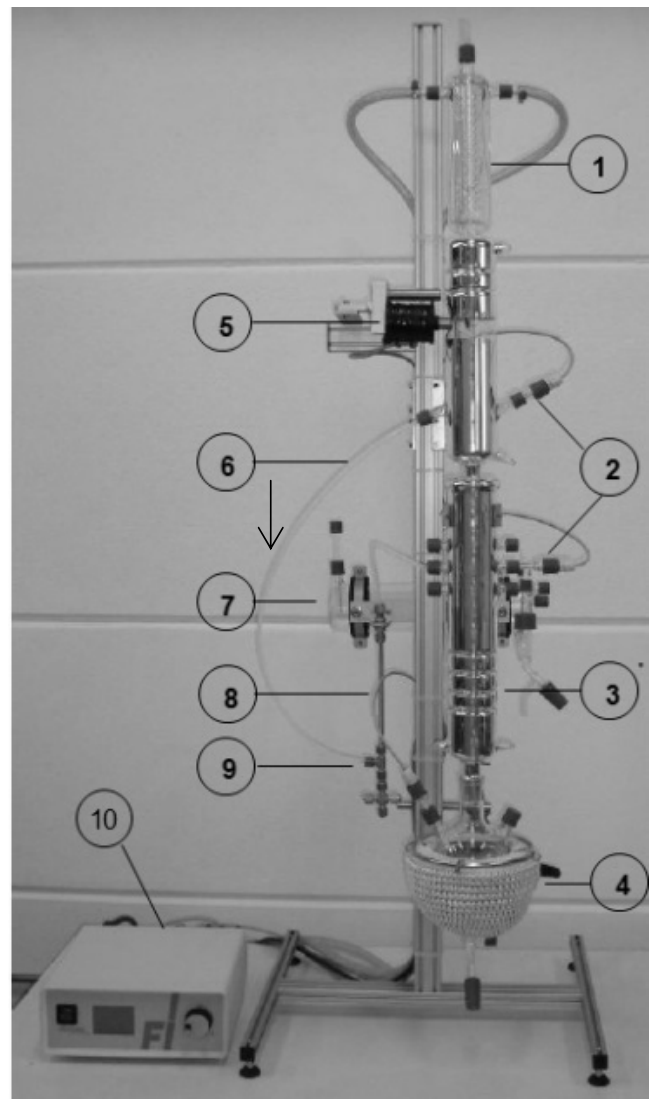

Fig. 2 Reactive distillation system. Legend: (1) condenser; (2) thermocouples; (3) RD column; (4) reboiler; (5) solenoid valve; (6) recycle; (7) decanter; (8) pre-reactor; (9) T-mixer; (10) controller; $(\downarrow)$ feed line [28].
2.5 Refining Processes by Using Hybrid Short Path Evaporation and Reactive Distillation

The refining processes were conducted in two steps: (1) lactic acid purification by using hybrid short path evaporation; and (2) by using reactive distillation.

In the first step, lactic acid diluted with distilled water was fed to the HSPE by using a peristaltic metering pump (Cole Palmer Masterflex model 77200-60). In this evaporation system, a trap is coupled to an external condenser that is continuously fed with liquid nitrogen $\left(-196{ }^{\circ} \mathrm{C}\right)$, freezing and avoiding the volatiles migrate to the pump and contaminate the oil. The vacuum system is composed by a mechanical pump. Table 2 describes the operating conditions used in the experiments. In this system it was possible to collect 03 streams: ICD (internal condenser distillate), ECD (external condenser distillate) and $\mathrm{R}$ (residue).

In the second step, the ICD stream from HSPE was fed to the RD system for the esterification reaction Eq. (1).

Esterification:

$$
\mathrm{C}_{3} \mathrm{H}_{6} \mathrm{O}_{3}+\mathrm{C}_{2} \mathrm{H}_{5} \mathrm{OH} \leftrightarrow \mathrm{C}_{5} \mathrm{H}_{10} \mathrm{O}_{3}+\mathrm{H}_{2} \mathrm{O}
$$

Lactic acid + ethanol $\leftrightarrow$ ethyl lactate + water

ICD and ethanol with sulfuric acid were fed in the middle of the column (7th tray from the bottom to the top) by using a peristaltic metering pump. The reactions were performed in a semi-batch RD column during $2 \mathrm{~h}$ at a total reflux ratio. After this time, reflux ratio was set to zero. Ethanol and water were collected predominantly in the distillate stream, while lactic acid, ethyl lactate, and sulfuric acid in the residue stream, which was further analyzed by CG for ethyl lactate quantification. Experiments were performed varying the reboiler temperature $\left(T_{\text {reb }}\right)$ and catalyst concentration (Cat wt \%). The operational conditions are shown in Table 3.

The residue stream of the esterification process was fed again in the same RD apparatus for the hydrolysis step Eq. (2). 
Table 2 Operational conditions used in hybrid short path evaporation system.

\begin{tabular}{llllll}
\hline $\mathrm{T}_{\text {evap }}\left({ }^{\circ} \mathrm{C}\right)$ & $\mathrm{T}_{\text {condint }}\left({ }^{\circ} \mathrm{C}\right)$ & $\mathrm{T}_{\text {condext }}\left({ }^{\circ} \mathrm{C}\right)$ & FFR $(\mathrm{mL} / \mathrm{min})$ & Agit $(\mathrm{rpm})$ & $\mathrm{P}(\mathrm{kPa})$ \\
\hline 132 & 16 & -5 & 14 & 750 & 1 \\
\hline
\end{tabular}

$\mathrm{T}_{\text {evap}}$ : evaporator temperature; $\mathrm{T}_{\text {condint }}$ internal condenser temperature; $\mathrm{T}_{\text {condext }}:$ external condenser temperature; FFR: feed flow rate; Agit: agitation; P: pressure.

Table 3 Operational conditions used in reactive distillation system for esterification reaction and results after the refining processes.

\begin{tabular}{llllll}
\hline Runs & MR & $\mathrm{T}_{\text {reb }}\left({ }^{\circ} \mathrm{C}\right)$ & Cat $(\mathrm{wt} \%)$ & YEL & $\%$ PR \\
\hline 1 & 5 & 100 & 4 & 37.05 & 14.69 \\
2 & 5 & 100 & 8 & 78.69 & 21.97 \\
3 & 5 & 150 & 4 & 95.10 & 18.15 \\
4 & 5 & 150 & 8 & 100.00 & 15.38 \\
\hline
\end{tabular}

$\overline{\mathrm{MR}}=$ molar ratio ethanol:lactic acid; $\mathrm{T}_{\mathrm{reb}}=$ reboiler temperature; Cat $=$ catalyst concentration; $\mathrm{YEL}=$ ethyl lactate yields; $\mathrm{PR}=$ lactic acid purity at residue.

Hydrolysis:

$$
\mathrm{C}_{5} \mathrm{H}_{10} \mathrm{O}_{3}+\mathrm{H}_{2} \mathrm{O} \leftrightarrow \mathrm{C}_{3} \mathrm{H}_{6} \mathrm{O}_{3}+\mathrm{C}_{2} \mathrm{H}_{5} \mathrm{OH}
$$

Ethyl lactate + water $\leftrightarrow$ lactic acid + ethanol

The diluted lactic acid solution was fed at the middle of the column. Hydrolysis was performed in a semi-batch mode at a partial reflux ratio. The hydrolysis occurred at $90{ }^{\circ} \mathrm{C}$ during $4 \mathrm{~h}$. The residue stream was further analyzed by HPLC.

\section{Results and Discussion}

Table 3 shows the ethyl lactate yields obtained in the experimental runs using HSPE-RD process. Ethyl lactate yield (YEL) was calculated by Eq. (3).

$$
Y_{E L}=\frac{\text { moles of ethyl lactate produced }}{\text { moles of lactic acid initial }}
$$

According to Table 3, the highest ethyl lactate yields were obtained in the run $3\left(\mathrm{MR}=5, \mathrm{~T}_{\text {reb }}=\right.$ $150{ }^{\circ} \mathrm{C}$, Cat wt. $\left.\%=4\right)$ and run $4\left(\mathrm{MR}=5, \mathrm{~T}_{\text {reb }}=\right.$ $150{ }^{\circ} \mathrm{C}$, Cat wt. $\%=8$ ), which were 95.10 and $100.00 \%$, respectively. The results showed that the yield of ethyl lactate can be increased with reaction temperature; however, at high temperatures other impurities are formed [31].

Comparing runs $1\left(\mathrm{MR}=5, \mathrm{~T}_{\mathrm{reb}}=100{ }^{\circ} \mathrm{C}\right.$, Cat wt. \% $=4)$ and $2\left(\mathrm{MR}=5, \mathrm{~T}_{\text {reb }}=100{ }^{\circ} \mathrm{C}\right.$, Cat wt. $\left.\%=8\right)$, which vary only the catalyst concentration; the increasing amount of catalyst resulted in a high ethyl lactate production. The YEL was increased in 2.12 times. The same behavior was observed in runs 3 (MR $=5, \mathrm{~T}_{\mathrm{reb}}=150^{\circ} \mathrm{C}$, Cat wt. $\left.\%=4\right)$ and $4\left(\mathrm{MR}=5, \mathrm{~T}_{\text {reb }}\right.$ $=150{ }^{\circ} \mathrm{C}$, Cat wt. $\%=8$ ), but the YEL increase was not pronounced, $95.10 \%$ and $100.00 \%$, respectively.

The results showed that lactic acid purity at residue range varied from $14.69 \%$ to $21.97 \%$. The highest ethyl lactate yield $21.97 \%$ was reached in run 2 . The initial lactic acid feed concentration was $4.71 \%$. The concentration process was responsible by producing a solution 4.7 times more concentrated. On the other hand, Cat wt. \% in run 2 is high which make necessary large sulfuric acid concentration in order to allow high yield. However, sulfuric acid in excess causes corrosion problems in the equipment. Heterogeneous catalyst, such as Amberlyst, is better than sulfuric acid. But the RD system used in this work consists on perforated plates and the use of heterogeneous catalyst could damage the equipment.

\section{Conclusion}

Lactic acid purification was studied using HSPE (hybrid short path distillation) and RD (reactive distillation) as coupled process. It was verified that it is possible to concentrate the lactic acid by using HSPE-RD. Lactic acid was obtained with content 4.7 times higher than the raw material concentration. 
Therefore, HSPE-RD is a good option for lactic acid separation and purification.

\section{Acknowledgement}

The authors are grateful to the financial support from São Paulo Research Foundation (FAPESP), Project $n^{\circ}$ 2015/12783-5.

\section{References}

[1] Ouyang, J., Ma, R., Zheng, Z., Cai, C., Zhang, M., and Jiang, T. 2013. "Open Fermentative Production of L-lactic Acid by Bacillus sp. Strain NL01 Using Lignocellulosic Hydrolyzates as Low-cost Raw Material." Bioresource Technol. 135: 475-80.

[2] Wang, Y., Meng, H., Cai, D., Wang, B., Qin, P., Wang, Z., and Tan, T. 2016. "Improvement of L-lactic Acid Productivity from Sweet Sorghum Juice by Repeated Batch Fermentation Coupled with Membrane Separation." Bioresource Technol. 211: 291-7.

[3] Abdel-Rahman, M. A., Tashiro, Y., and Sonomoto, K. 2013. "Recent Advances in Lactic Acid Production by Microbial Fermentation Processes." Biotechnol. Adv. 31: 877-902.

[4] Daful, A. G., Haigha, K., Vaskanb, P., and Görgensa, J. F. 2016. "Environmental Impact Assessment of Lignocellulosic Lactic Acid Production: Integrated with Existing Sugar Mills.” Food Bioprodu Process. 99: $58-70$.

[5] Wang, J., Wang, Q., Xu, Z., Zhang, W., and Xiang, J. 2015. Effect of Fermentation Conditions on L-lactic Acid Production from Soybean Straw Hydrolysate." J. Microbiol. Biotechnol. 25 (1): 26-32.

[6] Wee, Y. J., Kim, J. N., and Ryu, H. W. 2006. "Biotechnological Production of Lactic Acid and Its Recent Applications.” Food Technol. Biotechnol. 44 (2): 163-72.

[7] Wasewar, K. L., Heesink, A. B. M., Versteeg, G. F., and Pangarkar, V. G. 2002. "Reactive Extraction of Lactic Acid Using Alamine 336 in MIBK: Equilibria and Kinetics." J. Biotechnol. 97: 59-68.

[8] Datta, R., and Henry, M. 2006. "Lactic Acid: Recent Advances in Products, Processes and Technologies-A Review.” J. Chem. Technol. Biotechnol. 81: 1119-29.

[9] Chanukya, B. S., Kumar, M., and Rastogi, N. K. 2013. "Optimization of Lactic Acid Pertraction Using Liquid Emulsion Membranes by Response Surface Methodology." Sep. Purif. Technol. 111: 1-8.

[10] Kwak, H., Hwang, D. W., Hwang, Y. K., and CHANG, J. S. 2012. "Recovery of Alkyl Lactate from Ammonium
Lactate by an Advanced Precipitation Process." Sep. Purif. Technol. 93: 25-32.

[11] Min, D. J., Choi, K. H., Chang, Y. K., and Kim, J. H. 2011. "Effect of Operating Parameters on Precipitation for Recovery of Lactic Acid from Calcium Lactate Fermentation Broth." Korean J. Chem. Eng. 28 (10): 1969-74.

[12] Nakano, S., Ugwu, C. U., and Tokiwa, Y. 2012. "Efficient Production od D-(-)-lactic Acid from Broken Rice by Lactobacillus Delbrueckii Using $\mathrm{Ca}(\mathrm{OH})_{2}$ as a Neutralizing Agent.” Bioresource Technol. 104: 791-4.

[13] Alkaya, E., Kaptan, S., Ozkan, L., Uludag-demirer, S., and Demirer, G. N. 2009. "Recovery of Acids from Anaerobic Acidification Broth by Liquid-liquid Extraction." Chemosphere 77: 1137-42.

[14] Krzyzaniak, A., Leeman, M., Vossebeld, F., Visser, T. J., Schuur, B., and Haan, A. B. 2013. "Novel Extractantes for the Recovery of Fermentation Derived Lactic Acid." Sep. Purif. Technol. 111: 82-9.

[15] Yankov, D., Molinier, J., Albet, J., Malmary, G., and Kyuchoukov, G. 2004. "Lactic Acid Extraction from Aqueous Solutions with Tri-n-octylamine Dissolved in Decanol and Dodecano." Biochem. Eng. J. 21: 63-71.

[16] Pal, P., and Dey, P. 2013. "Process Intensification in Lactic Acid Production by Three Stage Membrane Integrated Hybrid Reactor System." Chem. Eng. Process. 64: 1-9.

[17] Ramchandran, L., Sanciolo, P., Vasiljevic, T., Broome, M., Powell, I., and Duke, M. 2012. "Improving Cell Yield and Lactic Acid Production of Lactococcuslactis ssp. Cremoris by a Novel Submerged Membrane Fermentation Process." J. Membrane Sci. 403-404: 179-87.

[18] Sikder, J., Roy, M., Dey, P., and Pal, P. 2012. "Techno-Economic Analysis of a Membrane-Integrated Bioreactor System for Production of Lactic Acid from Sugarcane Juice.” Biochem. Eng. J. 63: 81-7.

[19] Chen, L., Zeng, A., Dong, H., Li, Q., and Niu, C. 2012. "A Novel Process for Recovery and Refining of L-Lactic Acid from Fermentation Broth." Bioresource Technol. 112: 280-4.

[20] Komesu, A., Martins, P. F., Lunelli, B. H., Oliveira, J., Maciel, F. R., and Wolf, M. M. R. 2014. "Evaluation of Lactic Acid Purification from Fermentation Broth by Hybrid Short Path Evaporation Using Factorial Experimental Design." Sep. Purif. Tecnol. 136: 233-40.

[21] Xu, S. L., Zheng, T., and Xu, S. M. 2004. "The Study of Refining L-Lactic Acid by Molecular Distillation." Journal of Chemical Engineering of Chinese Universities 18: 246-9.

[22] Seo, Y., Hong, W. H., and Hong, T. H. 1999. "Effects of Operation Variables on the Recovery of Lactic Acid in a 
Batch Distillation Process with Chemical Reactions." Korean J. Chem. Eng. 16: 556-61.

[23] Kumar, R., Mahajani, S. M., Nanavati, H., and Noronha, S. B. 2006. "Recovery of Lactic Acid by Batch Reactive Distillation.” J. Chem. Technol. Biotechnol. 81: 1141-50.

[24] Asthana, N., Kolah, A., Vu, D. T., Lira, C. T., and Miller, D. 2005. "A Continuous Reactive Separation Process for Ethyl Lactate Formation." Org. Process Res. Dev. 9: 599-607.

[25] Lutisan, J., and Cvengros, J. 1995. "Mean Free Path of Molecular Distillation." The Chemical Engineering Journal 56: 39-50.

[26] Stankiewicz, A. I., and Moulijn, J. A. 2000. "Process Intensification: Transforming Chemical Engineering." Chem. Eng. Prog. 96: 22-34.

[27] Madzingaidzo, L., Danner, H., and Braun, R. 2002. "Process Development and Optimisation of Lactic Acid Purification using Electrodialysis." J. Biotechnol. 96: 223-9.
[28] Komesu, A., Martins, M. P. F., Lunelli, B. H., Maciel, F. R., and Wolf, M. M. R. 2015. "Lactic Acid Purification by Reactive Distillation System Using Design of Experiments." Chem. Eng. Process. 95: 26-30.

[29] Winkelnkemper, T., and Schembecker, G. 2010. "Purification Performance Index and Separation Cost Indicator for Experimentally Based Systematic Downstream Process Development." Sep. Purif. Tecnol. 72: 34-9.

[30] Rios, L. F., Martínez, E. L., da Silva, N. L., Dantas, T. S. S., MacielFilho, R. and Wolf, M. M. R. 2012. "Biodiesel Production by an Integrated Reactive Separation System: A Comparative Study." Chem. Eng. Trans. 26: 255-60.

[31] Barve, P. B., Kulkarni, B. D., Nene, S. N., Shinde, R. W., Gupte, M. Y., Joshi, C. N., Thite, G. A., Chavan, V. B., and Deshpande, T. R. 2007. Process for preparing 1- (+)lactic acid. USPatent WO/2007/010548 A1, filed December 30, 2005, and issued January 25. 